\title{
Entrevista a José Mattoso
}

\section{(2) OpenEdition}

1 Journals

\section{Edição electrónica}

URL: http://journals.openedition.org/medievalista/971

DOI: 10.4000/medievalista.971

ISSN: 1646-740X

\section{Editora}

Instituto de Estudos Medievais - FCSH-UNL

Refêrencia eletrónica

«Entrevista a José Mattoso », Medievalista [Online], 19 | 2016, posto online no dia 01 junho 2016, consultado no dia 21 abril 2019. URL : http://journals.openedition.org/medievalista/971 ; DOI : 10.4000/medievalista.971

(C) IEM 
Título: Entrevista a José Mattoso I Interview with José Mattoso

Fonte: Medievalista [Em linha]. Dir. Bernardo Vasconcelos e Sousa. Lisboa: IEM.

Disponível em:

http://www2.fcsh.unl.pt/iem/medievalista/MEDIEVALISTA19/entrevista1902.html

ISSN: 1646-740X

\section{Entrevista a José Mattoso}

Director da Medievalista OnLine desde o número 5 (2008) e até ao último número, o 18 (Julho-Dezembro de 2015), José Mattoso deixou este cargo por sua vontade expressa, tal como explicou então no Editorial da revista. A título de balanço, mas também de abertura de perspectivas para o futuro, impunha-se ouvir aquele que foi o principal responsável pelo crescimento e consolidação da Medievalista ao longo destes últimos sete anos. Às perguntas preparadas pela Redacção respondeu o nosso entrevistado em Novembro último. A sua reflexão ultrapassa o âmbito da revista, para se alargar à situação actual dos estudos medievais, da área das ciências sociais e das humanidades em Portugal.

- Como viu o lançamento da Medievalista há 10 anos e como avalia o percurso desde então feito pela revista?

A Medievalista foi fundada quando eu ainda estava em Timor. Não participei nas reuniões preparatórias promovidas pelo Luís Krus. Foi ele, portanto, o fundador. O meu papel foi o de apoio interessado, conselheiro, colega, amigo. Já estava reformado, mas participava, quando me era possível, em reuniões e provas académicas. Sendo, creio eu, o 
mais antigo dos membros do Departamento de História da FCSH-UNL, preferi manter-me à margem de iniciativas deste género, apoiar as que me parecessem válidas e meritórias e, se fosse necessário, ajudar a resolver as dificuldades e contradições.

Nessa altura considerei-a uma ideia excelente, mas para a concretização da qual me parecia não haver recursos suficientes. Sem nunca desencorajar o Luís, sentia-me um bocado céptico quanto ao seu êxito. Lembrava-me das várias revistas de História, impressas, fundadas em Portugal nos anos de 1930 a 1960, algumas delas por autores prestigiados, mas que raramente conseguiam sobreviver mais de dois ou três anos.

O certo é que o Luís com o seu low profile, modesto mas persistente, a sua paciência e a sua diplomacia, e sobretudo com a sua determinação, lá conseguiu lançar o primeiro número, e não deixou nunca de pôr todo o empenho na sua continuação. A sua persistência venceu as minhas dúvidas. Foram precisos alguns anos para, já depois da morte do Luís, a Medievalista se impor no "mercado" medievalístico nacional e até internacional. Creio que, no seu género, conseguiu uma audiência crescente junto de muitos centros de investigação medievalística da Europa e da América.

A razão deste sucesso creio que está na regularidade da sua publicação, na qualidade dos artigos de investigação que tem publicado e que revelam documentos importantes ou perspectivas originais, na informação acerca de projectos inovadores, no recenseamento de obras recém-publicadas, num bem informado anúncio de seminários, colóquios e congressos com alguma relação com a Idade Média, na preferência por temas e projectos inovadores de inspiração interdisciplinar (história das ciências, da mulher, dos marginais, das representações mentais, da guerra, de matérias hoje consideradas esotéricas etc., etc.). Tudo isto sem pretensões de cobrir sistematicamente as respectivas rubricas, nem de procurar sínteses abrangentes, mas prematuras. Assim, o volume e o interesse das suas informações, e o valor científico dos seus principais artigos têm vindo a aumentar. Tornou-se uma revista com razoável prestígio nos meios académicos. Conseguiu associar a investigação profissional a uma certa divulgação de conhecimentos, não propriamente para o grande público, nem para os investigadores altamente especializados, mas para os "amantes" ou "amadores" da Idade Média. Com efeito, podia ter enveredado pelo

Medievalista online № 19| Janeiro - Junho 2016 @ IEM - Instituto de Estudos Medievais 2 
formato de "magazine", à semelhança de outras revistas de história francesas, inglesas ou americanas bem conhecidas, mas que em Portugal nunca chegaram a ter grande sucesso. Prefiro o modelo que a Medievalista segue, do que qualquer outro modelo possível, entre outras razões, por se adaptar muito bem às condições próprias da informática e da Internet.

\section{- Qual é a sua visão sobre o estado actual dos estudos medievais em Portugal?}

Algumas das tendências actuais são muito nítidas. A mais saliente, na minha opinião, é a quantidade de publicações da área da História; a quantidade de centros, câmaras municipais, institutos, organismos e entidades de todo o género que publicam obras impressas ou participam na sua publicação; a quantidade de romances históricos, biografias, monografias, catálogos de exposições, folhetos informativos, conferências, colóquios, congressos, eu sei lá... O período histórico predominante talvez não seja a Idade Média. Mas em relação com o que antes do fim do milénio se editava acerca desse período, a produção deve ter duplicado ou triplicado. Não há Câmara Municipal que se preze que deixe de publicar pelo menos alguns folhetos acerca dos monumentos do seu território com fotografias e breves informações históricas.

Se a este conjunto se juntarem as teses de mestrado e doutoramento (e, mais recentemente, os resultados de projectos pós-doc), o número de publicações de tema medieval cresce ainda mais. Convém dizer, desde já, que a selecção dos trabalhos históricos em função da qualidade se tem tornado cada vez mais difícil. É frequente a publicação de textos e folhetos de má qualidade por entidades locais ou regionais que cuidam mais do aspecto do que do conteúdo, ou, até, que publicam obras luxuosas, mas não se preocupam com a qualidade do texto. Para as distinguir umas das outras não há nenhum filtro seguro. Pode até suceder publicarem-se trabalhos cheios de banalidades, onde aparecem pequenas pérolas no meio de muita palha; ou monografias aparentemente interessantes, mas puramente descritivas; ou obras que misturam dados importantes com dados secundários; ou listas de documentos bem ou mal seriados e referenciados, mas que o investigador não pode deixar de examinar; e assim sucessivamente.

Medievalista online № 19| Janeiro - Junho 2016 (c) IEM - Instituto de Estudos Medievais 3 
A esta profusão de dados cada vez mais difíceis de seleccionar e coordenar, juntem-se as comunicações a colóquios e congressos de todas as dimensões. O seu número não pára de crescer, as suas temáticas e conteúdos tanto podem ser irrelevantes como reveladoras de inesperados tesouros. Tanto seguem modelos clássicos como os da severa erudição germânica, como surpreendem pela sua inspiração em modelos nunca experimentados. Podem nascer da descoberta de núcleos documentais inéditos, ou então da exploração sistemática de séries documentais já conhecidas, mas interpretadas de maneira diferente. Pelos caminhos da interdisciplinaridade aparecem novas formas de datar, compreender ou contextualizar os testemunhos do passado: não apenas dos escritos, mas de todos os vestígios materiais do passado, quer os mais nobres, como as imagens, relíquias e insígnias, quer os anteriormente desprezados, como os instrumentos do trabalho manual, o vestuário, a olaria, as armas e, até, os restos de alimentos, as ossadas de animais, sem esquecer os pólens e outros vestígios da cobertura vegetal, etc., etc.

Estou a falar do vertiginoso aumento numérico de estudos, grandes e pequenos, que o medievalista pode ou tem de utilizar para conhecer e/ou compreender o passado. A massa de dados que o investigador pode, ou deve, usar, é de tal ordem que se torna cada vez mais difícil estabelecer listas bibliográficas completas para cada assunto (exigência outrora indispensável em provas académicas), quanto mais traçar o "estado da arte" que dê conta do progresso científico que academicamente se alcançou a respeito do ou dos problemas de que trata a dissertação. O desenvolvimento das modernas tecnologias da informação aperfeiçoou já enormemente as possibilidades da análise dos textos, e da criação de repertórios bibliográficos exaustivos para cada área das ciências sociais, quer repertórios completos até uma determinada data, quer repertórios periódicos da produção corrente. Espera-se que esses instrumentos de trabalho se tornem cada vez mais acessíveis.

Não devemos esquecer, porém, que o objectivo da investigação científica não é a quantidade, mas a qualidade. Ou seja, além de repertoriar tudo o que se produziu até à data da dissertação, é preciso assimilar o seu conteúdo, e assinalar aquilo que pode servir de apoio para o aprofundamento da questão em causa. A selecção da bibliografia depende de critérios irredutíveis (até agora) a indícios elementares, embora os actuais motores de

Medievalista online No 19| Janeiro - Junho 2016 (C) IEM - Instituto de Estudos Medievais 4 
busca informáticos se possam desde já usar em análises de dados linguísticos concretos, o que alarga enormemente a possibilidade de examinar conceitos e práticas adoptados pelos autores do passado ou pelas sociedades em que viveram. De qualquer maneira, a problemática historiográfica actual põe à prova a imaginação e a perspicácia do investigador, sem as quais a técnica fica reduzida a uma mecânica. Em vez de vivificar e fecundar a memória do passado, congelam-se os restos ou as marcas que ele deixou.

Agora reparo que as observações feitas até aqui dizem respeito ao medievalismo internacional. Mas a pergunta era acerca do medievalismo português. A situação é grosso modo análoga, isto é, a quantidade de publicações cresceu exponencialmente, mas a selecção qualitativa permite reduzir o que merece a pena ler. Por outro lado, a historiografia portuguesa vinha a perder qualidade desde a morte do seu patrono, Alexandre Herculano, quer porque o positivismo e o historicismo dominantes no pensamento europeu do fim do século XIX e primeira metade do XX eram de facto redutores, quer porque reduzia o estudo do passado ao elenco dos reis e das suas vitórias ou derrotas internas e externas, e à história das instituições interpretada à base do pensamento jurídico. $\mathrm{O}$ mito da decadência peninsular era compensado pela exaltação da heroicidade nacional que tinha levado os portugueses a espalhar a Fé e o Império até aos confins do Oriente. O salazarismo manteve e cultivou os dois mitos e reforçou-os com outros de inspiração político-institucional, como a não existência do feudalismo em Portugal, a ausência da luta de classes, a sólida e constante supremacia régia na sucessão do trono, na capacidade legislativa e na administração do território, etc., etc. A investigação científica e o ensino universitário em História transformaram-se em demonstrações de "teses" como as que referi. Os compêndios escolares e as obras de divulgação mantinham e glosavam o mesmo sentimento. Obcecada pelo mito da decadência, procurava resgatar a memória das derrotas sofridas proclamando o seu contrário. Ou seja, por meio de uma "verdade" que continha todas as outras e se traduzia graficamente sob o lema "Portugal não é um país pequeno".

No Portugal dos anos 60 a 80, o fosso, para não dizer o abismo, entre a historiografia científica e a historiografia do ensino e de divulgação era, pois, enorme. O conhecimento

Medievalista online № 19| Janeiro - Junho 2016 (c) IEM - Instituto de Estudos Medievais 5 
de outros métodos e outros problemas através de obras estrangeiras, sobretudo francesas, que faziam da História uma disciplina muito mais aliciante e convincente, veio, nos mesmos anos, a alimentar a crítica, mas não a inspirar a investigação. Exceptuam-se obras onde começava a despontar uma concepção moderna, como as de Magalhães Godinho e Oliveira Marques, publicadas fora de Portugal, ou as de Virgínia Rau, que se podem considerar sondagens dispersas não integradas num discurso interpretativo abrangente. As concepções marxistas ou estruturalistas e os progressos das ciências sociais, sobretudo da Antropologia, que, nos anos 60 a 74, opunham alunos a mestres, eram ainda concepções escolares, e continuaram a sê-lo até meados da década de 80. Só nessa altura começaram a inspirar expressamente dissertações de doutoramento e verdadeiras investigações originais susceptíveis de transformar a historiografia portuguesa e de a elevar até ao nível das obras francesas que tanto sucesso alcançaram até meados da década de 90. Nos anos seguintes, o nível da investigação científica parece-me ter estacionado, ao mesmo tempo que a produção aumentava em quantidade.

Sem poder, já, participar na renovação global e em sínteses interpretativas que dêem coerência a tudo o que a investigação crítica recentemente averiguou e sugeriu, creio que agora se impõe uma revisão geral e um trabalho comparativo em que os dados parcelares tenham o seu lugar e o seu sentido. É esse, creio eu, o desafio que as vossas perguntas me sugerem em nome da Medievalista. Não sei se há condições para fazer essa revisão com a amplitude e a pertinência de conceitos teóricos necessários, mas parece-me que, se não for feita, a imensa quantidade de dados que desde o princípio da década de 2000 se foi acumulando ficará estéril. Neste momento, talvez a profusão de estudos dos vestígios materiais estimulados pela interdisciplinaridade continue a sustentar a originalidade de novas pesquisas. Todavia, neste sector, a síntese é ainda mais problemática. Entretanto, a criação de centros de investigação como o IEM constitui também um factor muito importante nesta fase do medievalismo internacional. São sinais positivos de uma dinâmica possível, se da cooperação entre os investigadores nascerem as acções propostas por uma estratégia adequada.

Medievalista online № 19| Janeiro - Junho 2016 ( ) IEM - Instituto de Estudos Medievais 6 www2.fcsh.unl.pt/iem/medievalista 


\section{- Qual foi, é e poderá ser no futuro o contributo da Medievalista para os estudos medievais (utilidade, impacto...)?}

Parece-me que o editorial do último número (18) já dá uma impressão suficiente. No fundo trata-se de comparar o que se projectava inicialmente e aquilo que a Medievalista acabou por ser. Creio que há um alargamento dos temas, e um aprofundamento das análises. Ao mesmo tempo, cada vez maior variedade de abordagens. O número 18 é exemplo significativo disso mesmo.

As opções editoriais, o formato intelectual, o nível científico e o carácter inovador alcançados pela Medievalista podem-se, sem dúvida, encontrar separadamente noutras publicações congéneres. Mas, associados entre si, conferem-lhe características bastante próprias. O que certamente tem atraído os colaboradores é a relevância dos artigos pela novidade do seu conteúdo ou a originalidade do seu tratamento.

Como escrevi no Editorial do número 18, O lugar alcançado só se poderá manter se se sistematizarem os nossos programas, renovarem as nossas perspectivas, aprofundarem as nossas investigações e alargarmos o círculo dos nossos contactos. Ao passar o testemunho a um novo Director, espero que ele e a equipa redactorial continuem a dar vida ao projecto que Luís Krus concebeu, mas do qual só pôde lançar as primeiras sementes.

\section{- Qual é a sua opinião sobre as políticas de investigação científica no campo das ciências sociais, no nosso país?}

Essa questão é importante. Infelizmente, pouco sei dizer acerca dela sem consultar informações produzidas pelos próprios intervenientes nessas políticas.

Procurando na minha memória reminiscências dos meus contactos com a investigação e o ensino em Ciências Sociais, recordo a rejeição em bloco do seu próprio estatuto científico durante os últimos tempos do Estado Novo. Aparentemente o Regime receava que elas trouxessem só por si a divisão social, a contestação da autoridade e da lei, a inevitabilidade da luta política. Foi preciso a convicção e a persistência de Adérito Sedas

Medievalista online № 19| Janeiro - Junho 2016 (C) IEM - Instituto de Estudos Medievais 7 
Nunes para conseguir a aprovação do Gabinete de Investigações Sociais, antecessor do Instituto de Ciências Sociais, e a publicação dos primeiros resultados de inquéritos e de estudos da realidade social que em Portugal se realizaram. Entretanto o estudo oficial das realidades sociais praticava-se como subordinado aos estudos coloniais (Instituto Superior de Estudos Ultramarinos, depois Instituto Superior de Ciências Sociais e Política Ultramarina).

O 25 de Abril trouxe a libertação de tais preconceitos e a rápida multiplicação de centros de estudos. As Ciências Sociais diversificaram-se e especializaram-se em disciplinas como a Sociologia, a Antropologia, a Economia, a Ciência Política, a Psicologia Social, a Demografia, etc. Embora estas ciências procurassem definir princípios e conceitos intemporais, acabaram sempre por ter de considerar as coordenadas do espaço e do tempo. Inversamente, a História teve de considerar os conceitos e teorias fornecidos pela Sociologia e as outras ciências sociais para compreender e interpretar os fenómenos propriamente históricos. Por exemplo, as estruturas do parentesco para compreender os fenómenos da sucessão régia ou da origem e evolução da nobreza. Estas questões foram debatidas noutros países e entre nós à luz de obras de autores que tiveram então o maior sucesso, como Durkheim, Max Weber, Marcel Mauss, Michel Foucault, Levy-Strauss, etc., e contribuíram de facto para o aprofundamento historiográfico. Todavia a ideia de que a Sociologia pudesse contribuir de facto para a solução dos problemas reais da sociedade contemporânea, tais como o atraso económico português, a mortalidade infantil ou a subalternidade da mulher, foi dando o lugar ao cepticismo e à discussão teórica. Noutro registo, o dos métodos adequados à compreensão dos fenómenos sociais, pôs-se em dúvida o fundamento das "leis" até então formuladas e deu-se a prevalência aos "estudos de caso", ou seja à observação e averiguação dos comportamentos individuais e colectivos "em contexto" local e com duração reduzida, evitando as generalizações. No caso do Instituto de Ciências Sociais, que funcionou como uma espécie de epicentro de tais discussões, creio que tiveram bastante peso os membros que investigavam em História Moderna e Contemporânea, e não em Sociologia, que efectuaram investigações verdadeiramente inovadoras e obtiveram grande sucesso editorial (como Vasco Pulido Valente, Filomena Mónica, Fátima Bonifácio, Nuno Monteiro, António Hespanha, Rui 
Ramos...), em contraste com a reduzida notoriedade dos seus colegas sociólogos, salvo raras excepções. Fátima Bonifácio, por exemplo, não hesitava em considerar as ciências sociais praticadas em França como um irremediável fracasso. Ao mesmo tempo, à medida que os seus modelos iam perdendo credibilidade, ia-se consolidando a influência anglo-saxónica. De resto quase todos estes investigadores eram de formação inglesa.

Entretanto, o prestígio científico global das Humanidades e das Ciências Sociais ia decaindo, nos anos 80 e 90, em favor das Ciências Exactas e das Tecnologias. A maioria dos Ministros da Educação tinham uma formação em Ciências Exactas. As verbas estatais para o desenvolvimento científico e tecnológico reservavam-se, na sua maior parte, para as Ciências, deixando os restos para as Humanidades. A inferioridade daí resultante agravou-se com a aplicação dos mesmos critérios de avaliação aos projectos de investigação apresentados a concurso, quer fossem científicos, quer humanísticos. Concebidos para as Ciências Exactas, distorciam os resultados dos projectos humanísticos. Se, apesar de tudo, a História foi, nessa mesma época, melhorando os seus resultados, não ficou a devê-lo aos estímulos estatais, mas à sua própria dinâmica e ao interesse que, nos mesmos anos, suscitava na opinião pública, como se verificou, por exemplo, com o êxito editorial da História de Portugal do Círculo de Leitores. Com efeito, mesmo tendo em conta que a investigação nas ciências "duras" é, por sua própria natureza, mais cara que nas Humanidades, pode-se considerar que as verbas atribuídas a estas as reduziam a um papel, por assim dizer, puramente ornamental. Os organismos governamentais que ditaram as políticas da formação humana nunca souberam estimular a Ciência sem inferiorizar a Arte e o Pensamento. A única excepção de relevo neste panorama foi Mariano Gago. A excepção que confirma uma regra que se mantém até hoje.

6 de Novembro de 2015.

Medievalista online № 19| Janeiro - Junho 2016 (c) IEM - Instituto de Estudos Medievais 9 www2.fcsh.unl.pt/iem/medievalista 


\section{COMO CITAR ESTE ARTIGO}

\section{Referência electrónica:}

\section{“Entrevista a José Mattoso".}

Medievalista [Em linha]. №19 (Janeiro - Junho 2016). [Consultado dd.mm.aaaa].

Disponível em

http://www2.fcsh.unl.pt/iem/medievalista/MEDIEVALISTA19/entrevista1902.html ISSN 1646-740X.

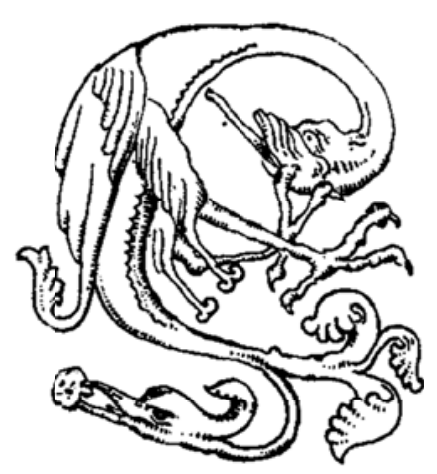

Medievalista online No 19| Janeiro - Junho 2016 (c) IEM - Instituto de Estudos Medievais 10 www2.fcsh.unl.pt/iem/medievalista 